\title{
FAKTOR YANG BERHUBUNGAN DENGAN KELELAHAN KERJA PADA PEKERJA INDUSTRI MEBEL DI KECAMATAN TEMPE KABUPATEN WAJO
}

Factors Related to Work Fatigue on Industrial Workers

in Tempe District Wajo Regency

Astrie Wahyuni, Rasman dan Ain Khaer

Jurusan Kesehatan Lingkungan Poltekkes Kemenkes Makassar astriewhyuni99@gmail.com

\begin{abstract}
Work fatigue can result in a decrease in performance which results in both formal and informal types of work, thus causing fatigue which results in an increase in work errors that lead to work accidents. This study aims to determine the factors associated with work fatigue in furniture industry workers in Tempe District, Wajo Regency. This type of research is an Analytical Survey using a Cross Sectional approach, the sampling technique used is Total Sampling, a sample of 45 workers from 10 Furniture Industries and analyzed using the Chii Square test. The results showed that there was no relationship between age and work fatigue > 0.074 , there was a relationship between length of work and work fatigue 0.007 , there was a relationship between years of service and work fatigue 0.002, there was a relationship between work attitude and work fatigue 0.009. The conclusion in this study there is no relationship between age and work fatigue and there is a relationship between length of work, tenure and work attitude with work fatigue. Provide education to SMEs in the Furniture Industry about the comfort factor in working in order to reduce the level of work fatigue and can improve the performance of workers.
\end{abstract}

Keywords: Age, Length of Work, Period of Work, Work Attitude.

\section{ABSTRAK}

Kelelahan kerja dapat mengakibatkan penurunan kinerja yang berakibat pada jenis pekerjaan baik formal maupun informal, sehingga menyebabkan kelelahan yang berakibat pada peningkatan kesalahan kerja yang berujung pada kecelakaan kerja. Penelitian ini bertujuan untuk mengetahui faktor yang berhubungan dengan kelelahan kerja pada pekerja Industri Mebel di Kecamatan Tempe Kabupaten Wajo. Jenis penelitian ini adalah Survei Analitik dengan menggunakan pendekatan Cross Sectional, teknik sampling yang digunakan yaitu Total Sampling, sampel berjumlah 45 pekerja dari 10 Industri Mebel dan dianalisis menggunakan uji Chii Square. Hasil penelitian menunjukkan bahwa tidak ada hubungan antara umur dengan kelelahan kerja $>0,074$, ada hubungan antara lama kerja dengan kelelahan kerja $\leq 0,007$, ada hubungan antara masa kerja dengan kelelahan kerja $\leq 0,002$, ada hubungan antara sikap kerja dengan kelelahan kerja $\leq 0,009$. Kesimpulan dalam penelitian ini tidak terdapat hubungan antara umur dengan kelelahan kerja dan terdapat hubungan antara lama kerja, masa kerja dan sikap kerja dengan kelelahan kerja. Memberikan edukasi pada UKM di Industri Mebel tentang faktor kenyamanan dalam bekerja agar dapat mengurangi tingkat kelelahan kerja dan dapat meningkatkan kinerja pada pekerja.

Kata Kunci: Umur, Lama Kerja, Masa Kerja, Sikap Kerja

\section{PENDAHULUAN}

Kesehatan dan Keselamatan Kerja ialah salah satu jenis upaya yang dilakukan untuk mengklaim keutahan baik fisik juga batin khususnya bagi tenaga kerja dan biasanya bagi manusia, akan menuju masyarakat jujur dan sejahtera. Kesehatan dan Keselamatan Kerja bukan hanya tentang keamanan fisik tetapi melibatkan beberapa unsur dan pihak (Sunaryo, 2017).

Kelelahan kerja menggambarkan kondisi dimana aktivitas individu sudah tidak kuat lagi melakukan pekerjaannya. Dengan istilah lain, kelelahan kerja akan memicu terjadinya penurunan kerja yang bisa berdampak pada meningkatnya kelalaian kerja dan berakhir dalam kecelakaan kerja (Nurmianto, 2004).

Faktor penyebab kelelahan antara lain kerja fisik yang membutuhkan aktivitas otot, kerja mental yang melibatkan otak, cara kerja yang salah dapat menimbulkan kelelahan dan luka, serta lingkungan kerja yang tidak nyaman dapat menurunkan produktivitas dan menyebabkan kelelahan (Suma'mur, 2009). Data dari International Labour Organization (ILO) pada tahun 2018 menyatakan pertahunnya terdapat 2 juta orang yang meninggal akibat dampak kelelahan. Di Indonesia pada tahun 2018 dari 847 masalah terdapat $36 \%$ kasus kecelakaan kerja yang ditimbulkan dari kelelahan, dan 64\% masalah yang ditimbulkan dari hal lain.

Berdasarkan Penelitian Linda Prastika (2019) menyatakan bahwa tenaga kerja mebel di Desa Serenan mengalami kelelahan kerja diakibatkan beberapa faktor seperti sikap kerja, beban kerja dan lama kerja (Prastika, dkk, 2019).

Kabupaten Wajo adalah Kabupaten yang ada di Sulawesi Selatan dikenal akan laju bisnis yang layak bersaing dibidang bisnis dan kerajinan mebel. Kecamatan Tempe merupakan salah satu kawasan kota yang memiliki lahan yang cukup luas yang dilengkapi oleh prasarana yang cukup berkembang, sehingga mendorong masyarakat untuk meningkatkan derajat kehidupan tepatnya di Kecamatan Tempe.

Hasil observasi awal yang dilakukan peneliti pada pekerja mebel, saat bekerja para pekerja memiliki pekerjaan yang berbeda-beda ada yang angkut mengangkut kayu, melakukan penggergajian kayu biasanya dalam bentuk manual maupun mekanis, memotong dan mengukir kayu, pengamplasan, pengecetan, serta pada tahan pengkilapan. Sikap kerja pekerja mebel pada umumnya tidak ergonomis. Pekerja pada saat melakukan pekerjaannya acapkali jongkok dan membungkuk, serta tidak memakai penyangga atau kursi untuk duduk. 
Jurnal Sulolipu : Media Komunikasi Sivitas Akademika dan Masyarakat

Vol. 21 No.2 2021

e-issn : 2622-6960, p-issn : 0854-624X

Dari hasil wawancara yang dilakukan, pekerja sering mengeluhkan gejala seperti sakit kepala, kram otot dan nyeri punggung, sulit memusatkan perhatian dan tremor pada seluruh anggota badan. Umur para pekerja memiliki berbedaan antara 17-50 tahun. Pekerja tersebut telah lama bekerja sebagai pekerja mebel yaitu 3-5 tahun. Pekerja mebel terkadang bekerja hingga lembur untuk menyelesaikan pesanan mebel. Untuk produksi mebel itu sendiri dikerjakan biasanya dalam sehari terdapat 2 jenis mebel yang dapat diselesaikan dalam artian dalam 4 hari pekerja mebel dapat menghasilkan 8 jenis mebel. Adapun pekerja yang dipekerjakan adalah masyarakat yang bertempat tinggal disekitaran mebel dan ada beberapa pekerja yang didatangkan langsung dari luar kota yaitu dari Pulau Jawa.

\section{METODE}

Desain penelitian ini adalah Survei Analitik dengan pendekatan cross sectional, dengan metode pengambilan sampel dengan teknik Total Sampling. Penelitian dilakukan pada bulan April-Mei 2021. Sampel dalam penelitian ini pekerja Industri Mebel di Kecamatan Tempe Kabupaten Wajo berjumlah 45 orang dari 10 Industri Mebel dengan menggunakan Uji Chii Square.

\section{PEMBAHASAN}

\section{Hubungan antara Umur dengan Kelelahan Kerja}

Berdasarkan data hasil penelitian pada pekerja Industri Mebel di Kecamatan Tempe Kabupaten Wajo berdasarkan umur yaitu pada umur muda terdapat 12 responden (27\%) dan pada umur tua terdapat responden $33 \quad(73 \%)$ yang mengalami kelelahan kerja. Hasil uji statistik didapatkan bahwa tidak ada hubungan umur dengan kelelahan kerja pada pekerja Industri Mebel di Kecamatan Tempe Kabupaten Wajo berdasarkan hasil uji chii square dengan nilai $p=0,074>0,05$. Hal ini dipengaruhi karena pada umur $>40$ tahun terjadi penurunan kekuatan otot ditandai dengan rasa pegal-pegal (Prasnowo dkk, 2020). Keluhan pada otot skeletal dirasakan pada pekerja. Keluhan nyeri otot disebabkan karena otot menerima beban secara terusmenerus dalam jangka waktu yang lama. Penyebabnya adalah penegangan otot yang berlebihan, aktivitas berulang, dan perilaku kerja yang tidak alami sebagai akibatnya menurunnya kemampuan organ sehingga bisa mengakibatkan pekerja mengalami kelelahan, tetapi keadaan ini diimbangi dengan stabiltas emosi yang stabil dan bisa menyesuaikan diri dengan lingkungan berdasarkan keahlian sehingga dapat bekerja lebih lancar dan terampil. Beberapa pekerja yang umurnya $>40$ tahun merupakan pekerja yang didatangkan langsung oleh pemilik mebel dari Jawa, seperti yang diketahui bahwa Jawa merupakan tempat produksi mebel yang terkenal dikalangan masyarakat, dibandingkan dengan umur yang $\leq 20-40$ tahun mempunyai keterampilan yang lebih tinggi, tapi kerap mengalami kelelahan akibat kecerobohan dan sikap tergesa-gesa (Triwibowo dkk, 2020). Hal ini dipengaruhi oleh tekanan kerja secara terus-menerus dan pengaturan jam kerja yang tidak optimal, sehingga muncul kecenderungan akibat terjadinya kelelahan, gangguan kesehatan dan kecelakaan kerja.

Penelitian ini searah dengan yang dilakukan Wulan Rilam Sari (2019) yang mengatakan tidak ada hubungan umur dengan kelelahan kerja. Dimana tenaga kerja yang umurnya sudah tua keadaan fisiknya kurang, namun pekerjaannya rajin dan terampil, sedangkan pada umur muda memiliki fisik yang kuat, inovatif dan semangat, namun cepat bosan.

Hal ini bertolak belakang dengan pendapat Triwibowo yang menyatakan makin tua umur seorang, maka makin besar tingkat kelelahannya.

\section{Hubungan antara Lama Kerja dengan Kelelahan Kerja.}

Berdasarkan data terdapat 13 responden (29\%) yang lama kerjanya memenuhi syarat yaitu bekerja $\leq 8$ jam perhari dan 32 responden $(71 \%)$ yang lama kerjanya tidak memenuhi yaitu > 8 jam perhari. Hasil uji statistik didapatkan bahwa ada hubungan lama kerja dengan kelelahan kerja pada pekerja Industri Mebel di Kecamatan Tempe Kabupaten Wajo berdasarkan hasil uji chii square dengan nilai $p=0,007 \leq 0,05$. Penyebab kelelahan pada pekerja yaitu akibat kondisi lingkungan yang panas. Kondisi lingkungan yang panas dapat menyebabkan pekerja mengalami dehidrasi. Kekurangan cairan terjadi oleh penambahan kebutuhan cairan pengaruh suhu lingkungan serta tidak diimbangi dengan asupan cairan yang cukup. Suhu lingkungan yang tinggi memicu pengeluaran cairan tubuh melalui pernafasan dan keringan meningkat, sehingga muncul gejala seperti haus, tidak fokus, dan mudah mengantuk.

Berdasarkan wawancara yang 
dilakukan, pekerja mebel mulai bekerja dari jam 07.00-17.00 WITA bergantung dari banyaknya jumlah orderan, sehingga biasanya mendapatkan tuntutan waktu lembur. Pekerja dituntut untuk bisa melakukan semua jenis pekerjaan yang membutuhkan ketelitian, fokus, serta terampil yang memungkinkan munculnya kelelahan akibat bekerja dengan waktu yang lama, yang kemudian memicu timbulnya perasaan bosan atau jenuh dengan aktivitas bekerja. Penambahan waktu lembur pada pekerja yaitu selama 2 jam, sedangkan waktu kerja lembur yang efisien adalah 30 menit, sehingga para pekerja sering mengeluhkan kaku pada saat bergerak. Keluhan ini muncul ketika pekerja melakukan semua jenis pekerjaan sekaligus pada waktu yang lama.

Undang-Undang tentang Ketenagakerjaan No. 13 tahun 2003 menyatakan bahwa lamanya seorang bekerja dalam sehari ialah 8 atau 40 jam seminggu dengan waktu istirahat yaitu setengah jam setelah bekerja selama 4 jam dan waktu istirahat tidak termasuk jam kerja. Memperpanjang waktu kerja dari kemampuan lama kerja dan menunda waktu istirahat umumnya terlihat penurunan kualitas dan hasil kerja sehingga cenderung muncul kelelahan, gangguan kesehatan dan kecelakaan kerja.

Penelitian ini searah dengan yang dilakukan Dyah Dewi Hastuti (2015) yang mengatakan ada hubungan lama kerja dengan kelelahan kerja pada pekerja konstruksi PT. Nusa Raya Cipta, disebabkan oleh waktu kerja yang beresiko adalah $>8$ jam perhari, meskipun tidak semua memiliki jam kerja yang beresiko.

Hal ini searah dengan pernyataan Suma'mur bahwa makin lama waktu kerja, maka kemungkinan besar terjadi hal yang buruk bagi pekerja yang bersangkutan maupun pekerja itu sendiri.

Kelelahan dapat dikurangi dengan istirahat yang cukup untuk memberikan kesempatan bagi pekerja untuk kembali membangun energi yang telah digunakan demi mengerjakan orderan.

\section{Hubungan antara Masa Kerja dengan Kelelahan Kerja}

Berdasarkan data yang diperoleh dari penelitian pada pekerja Industri mebel di Kecamatan Tempe Kabupaten Wajo berdasarkan masa kerja diketahui maka dari 11 pekerja mebel yang masa kerjanya baru $\leq 5$ tahun terdapat 7 pekerja $(64 \%)$ yang mengalami kelelahan kerja dan 4 responden $(36 \%)$ yang tidak mengalami kelelahan kerja. Sedangkan dari 34 pekerja mebel yang masa kerjanya lama $\geq 5$ tahun terdapat 33 pekerja (97\%) yang mengalami kelelahan kerja dan 1 responden (3\%) yang tidak mengalami kelelahan kerja. Hasil uji statistik menggunakan uji Chii Square yaitu nilai $p=0.002$ karena $p \leq 0.05$, maka dapat disimpulkan ada hubungan masa kerja dengan kelelahan kerja pada pekerja Industri Mebel di Kecamatan Tempe Kabupaten Wajo.

Hasil penelitian menunjukkan terdapat hubungan masa kerja dengan kelelahan kerja dipengaruhi karena cenderung memiliki masa kerja lama $>5$ tahun sehingga mempunyai risiko lebih cepat mengalami kelelahan karena aktivitas kerja yang lama setiap harinya dibandingkan dengan pekerja yang masa kerjanya masih baru. Salah satu faktor penyebabnya ialah lingkungan kerja, dimana keadaan lingkungan kerja yang ada di tempat pembuatan mebel tidak terlepas dari mesin produksi yang sedang berproses yang mempunyai dampak tidak baik bagi pekerja, seperti pada saat proses produksi mebel yaitu pada tahap penggergajian yang tidak hanya memakai gergaji secara mekanis tetapi juga menggunakan gergaji yang besar. Mekanisme ini memicu abu berlebihan dan dapat memicu bunyi, serta mesin yang digunakan. Kondisi seperti ini dialami pekerja setiap harinya yang bisa mengganggu kenyamanan saat bekerja yang dapat memicu terjadinya kelelahan dan dapat menyebabkan timbulnya kesalahan kerja karena tidak konsentrasi yang memicu timbulnya keluhan.

Penelitian ini searah dengan yang dikemukakan oleh P.Elia (2015) mengatakan ada hubungan antara masa kerja dengan kelelahan kerja, dimana seorang yang masa kerjanya lama sering mengalami kelelahan dibandingkan dengan seorang yang masa kerjanya baru.

Hal ini searah dengan pernyataan Suma'mur bahwa makin lama masa kerja seorang akan memberikan pengaruh negatif sehingga mengakibatkan keletihan dan kejenuhan serta semakin terpapar risiko yang ada pada lingkungan kerja.

\section{Hubungan antara Sikap Kerja dengan Kelelahan Kerja.}

Dari penelitian terhadap pekerja Industri mebel di Kecamatan Tempe Kabupaten Wajo diketahui bahwa dari 45 responden diketahui total pekerja dengan sikap kerja ergonomis sebanyak 8 orang 
(18\%) dan pekerja dengan sikap kerja yang tidak ergonomis sebanyak 37 orang (82\%). Hasil uji statistik menggunakan uji Chii Square yaitu nilai $p=0.009$ karena $p \leq 0.05$, sehingga disimpulkan bahwa ada hubungan sikap kerja dengan kelelahan kerja. Hal ini diakibatkan karena adanya aktivitas tubuh dimana para tenaga pekerja tidak mengerjakan satu jenis pekerjaan saja, tetapi semua jenis pekerjaan yang menyangkut proses produksi mebel.

Berdasarkan hasil observasi menunjukkan bahwa sikap kerja pada pekerja Industri Mebel di Kecamatan Tempe Kabupaten Wajo diamati melalui bagaimana sikap kerja pekerja pada saat bekerja yaitu pada saat proses penggerajian kayu yang ada dalam jenis kayu gelondongan sehingga masih harus digergaji supaya ukurannya menjadi lebih kecil. Sikap kerja pada proses penggergajian yaitu berdiri terlalu lama bahkan sampai $>2$ jam secara terusmenerus sangat mungkin memicu munculnya akumulasi cairan dan berbagai darah bagi kaki. perilaku kerja duduk yang lama saat proses pengukiran dengan posisi yang keliru dapat menyebabkan otot rangka termasuk tulang belakang merasa mudah lelah dan nyeri. Beberapa pekerja menggunakan kaleng cat untuk dudukan yang tidak sesuai dengan posisi tubuh pekerja sehingga menekan pembuluh darah secara tidak langsung juga akan menghambat transfer energy dan oksigen yang dibutuhkan.

Sikap kerja membungkuk pada saat proses perakitan dan pembentuk mebel dilakukan pemasangan memakai baut, perekat, dan paku akan melekatkan bagian dengan sikap kerja yang tidak ergonomis, akan menyebabkan tekanan pada bantalan saraf lebih besar. Selain itu jenis pekerjaan seperti pengamplasan pada tahap akhir proses produksi mebel yang membutuhkan ketelitian secara tidak sadar, misalnya membungkuk dan memutar punggung agar dapat melihat objek dengan jelas. Perilaku kerja yang janggal pada durasi yang lama mengakibatkan otot punggung berkontraksi statis tidak mendapatkan oksigen dari darah. Kemampuan berkontraksi yang mengakibatkan terjadinya nyeri pada punggung ( Suma'mur, 2013).

Penelitian ini searah dengan yang dilakukan Nurwinda (2019) bahwa ada hubungan sikap kerja dengan kelelahan kerja yang ditimbulkan posisi kerja yang tidak ergonomis ketika mengerjakan orderan.

Posisi pekerja yang tidak efisien bisa menimbulkan kelelahan dan luka dalam otot. perilaku pekerja yang tidak alamia ialah perilaku pekerja yang mengakibatkan sikap anggota badan beranjak menghindari sikap alamia, seperti perilaku menjangkau barang yang melebihi jangkauan tangan wajib dihindarkan (Saleh dkk, 2008).

Untuk mengurangi taraf kelelahan seorang pekerja sebaiknya menghindari perilaku pekerja yang statis dan diusahakan perilaku pekerja yang bervariasi. Hal ini bisa dilakukan dengan mengubah perilaku pekerja yang statis menjadi perilaku yang dinamis, sebagai akibatnya aliran darah dan oksigen bisa berfungsi baik ke semua anggota tubuh (Tarwaka, 2020).

\section{KESIMPULAN}

1. Tidak Ada hubungan antara Umur dengan kelelahan kerja pada pekerja Industri Mebel di Kecamatan Tempe Kabupaten Wajo.

2. Ada hubungan antara Lama Kerja dengan kelelahan kerja pada pekerja Industri Mebel di Kecamatan Tempe Kabupaten Wajo.

3. Ada hubungan antara Masa Kerja dengan kelelahan kerja pada pekerja Industri Mebel di Kecamatan Tempe Kabupaten Wajo.

4. Ada hubungan antara Sikap Kerja dengan kelelahan kerja pada pekerja Industri Mebel di Kecamatan Tempe Kabupaten Wajo.

\section{SARAN}

1. Memberikan edukasi pada UKM pada Industri Mebel mengenai aspek kenyamanan dalam bekerja agar mengurangi tingkat kelelahan kerja dan dapat meningkatkan kemampuan pada pekerja.

2. Diharapkan kepada pekerja untuk lebih memperhatikan waktu kerja untuk beristirahat yang cukup saat merasakan kelelahan apabila kepada pekerja yang masa kerjanya sudah $>5$ tahun supaya terhindar dari hal yang dapat merugikan pekerja itu sendiri.

3. Diharapkan kepada pekerja untuk lebih memperhatikan posisi kerja yang ergonomis agar tidak terjadi keluhan yang bisa mengakibatkan kelelahan kerja.

4. Diharapkan kepada peneliti berikutnya untuk mengkaji variabel yang belum diteliti sebelumnya yaitu kondisi lingkungan seperti kelembaban,suhu, dan kebisingan. 
Jurnal Sulolipu : Media Komunikasi Sivitas Akademika dan Masyarakat

Vol. 21 No.2 2021

e-issn : 2622-6960, p-issn : 0854-624X

\section{DAFTAR PUSTAKA}

Aries. 2015. Penyakit Akibat Kerja. Jakarta. PT. Elex Media Komputindo.

Kelurahan, D. I., Kecamatan, K., \& Tengah, S. (2017). Analisis Hubungan Beban Kerja Fisik, Masa Kerja, Usia, Dan Jenis Kelamin Terhadap Tingkat Kelelahan Kerja Pada Pekerja Bagian Pembuatan Kulit Lumpia Di Kelurahan Kranggan Kecamatan Semarang Tengah. Jurnal Kesehatan Masyarakat (e-Journal), 5(5), 413-423. (online) https://ejournal3.undip.ac.id/index.php/jkm/article/view/18963 (diakses tanggal 25 Desember 2020).

Kurniawidjaja LM. 2012. Teori Dan Aplikasi Kesehatan Kerja. Jakarta. Universitas Indonesia;.

Mulyadi M, Nurwinda N. 2019. Analisis Faktor Penyebab Kelelahan Pekerja Di Pt. Top Saba Mandiri Food Makassar. Sulolipu Media Komun Sivitas Akad dan Masy.;17(1):15.doi:10.32382/sulolipu.v18i1.722.(online).http://www.journal.poltekkesmks. ac.id/ojs2/index.php/Sulolipu/article/view/722 (diakses tanggal 29 Desember 2020).

Mulyadi M, Arminah N. 2019. Analisis Faktor-Faktor Yang Memengaruhi Kelelahan Kerja Pada Pekerja Mebel Di Kecamatan Manggala Kota Makassar. Sulolipu Media Komun Sivitas Akad dan Masy.

;18(2):184.doi:10.32382/sulolipu.v18i2.1155.(online).http://journal.poltekkes-

mks.ac.id/ojs2/index.php/Sulolipu/article/view/1155 (diakses tanggal 5 Januari 2021).

Nurmianto E. 2008. Ergonomi: Konsep Dasar Dan Aplikasinya. Surabaya. Gunawidya; Perindustrian RI. 2017. Industri Mebel Tumbuh Tujuh Persen (online) https://kemenperin.go.id/artikel/5799/Industri-Mebel-Tumbuh-7-Persen (diakses tanggal 20 Desember 2020)

Prastika L, Sri Darnoto, SKM M, Dwi Astuti, SKM MK, Rezannia Asyfiradayati, SKM. M. 2019. Hubungan Postur Kerja dengan Kelelahan Kerja pada Pekerja Mebel di Desa Serena, Juwiring, Klaten. J Chem Inf Model;53(9):1689-1699 (online) http://eprints.ums.ac.id/74493/ (diakses tanggal 7 Januari 2021).

Reppi, G. C., Suoth, L. F., \& Kandou, G. D. 2019. Hubungan antara Beban Kerja Fisik dengan Kelelahan Kerja pada Pekerja Industri Pembuatan Mebel Kayu di Desa Leilem Satu. Medical Scope Journal, 1(1), 21-25 (online) https://doi.org/10.35790/msj.1.1.26629 (diakses tanggal 5 Januari 2021).

Santoso G. 2004. Ergonomi Manusia, Peralatan Dan Lingkungan. Jakarta. Prestasi Pustaka Publisher;

Suma'mur. 2009. Higiene Perusahaan Dan Keselamatan Kerja. Jakarta. CV Sagung Seto;.

Sunaryo W. 2017. Ergonomi Dan K3. Bandung. PT Remaja Rosdakarya Offset;:

Tambuwun, J. H., Malonda, N. S. H., \& Kawatu, P. A. T. 2020. Hubungan Antara Usia dan Masa Kerja dengan Keluhan Muskulo-skeletal pada Pekerja Mebel di Desa Leilem Dua Kecamatan Sonder. Medical Scope Journal, 1(2), 1-6. (online) https://doi.org/10.35790/msj.1.2.2020.27201 (diakses tanggal 7 Januari 2021).

Tarwaka. 2004. Ergonomi Untuk Keselamatan, Kesehatan Kerja, dan Produktivitasnya. Surakarta. UNIBA Press.

Triwibowo C, Pushandani ME. 2013. Kesehatan Lingkungan Dan K3. Yogyakarta. Nuha Medika. 
Jurnal Sulolipu : Media Komunikasi Sivitas Akademika dan Masyarakat

Vol. 21 No.2 2021

e-issn : 2622-6960, p-issn : 0854-624X

Tabel 1

Distribusi Frekuensi Responden Berdasarkan Kelelahan Kerja Sumber: Data Primer Tahun 2021.

\begin{tabular}{lcc}
\hline Kelelahan Kerja & Frekuensi & Persentase (\%) \\
\hline Lelah & 45 & 89 \\
Tidak Lelah & 0 & 11 \\
\hline Total & 45 & 100 \\
\hline
\end{tabular}

Sumber: Data Primer Tahun 2021.

Tabel 2

Distribusi Frekuensi Responden Berdasarkan Umur

\begin{tabular}{ccc}
\hline Umur & Frekuensi & Persentase $(\%)$ \\
\hline$\leq 20-40$ tahun & 12 & 27 \\
$>40$ tahun & 33 & 73 \\
\hline Total & 45 & 100 \\
\hline
\end{tabular}

Sumber: Data Primer Tahun 2021.

Tabel 3

Distribusi Frekuensi Responden Berdasarkan Lama Kerja

\begin{tabular}{ccc}
\hline Lama Kerja & Frekuensi & Persentase $(\%)$ \\
\hline$\leq 8$ jam perhari & 13 & 29 \\
$>8$ jam perhari & 32 & 71 \\
\hline Total & 45 & 100 \\
\hline
\end{tabular}

Sumber: Data Primer Tahun 2021.

Tabel 4

Distribusi Frekuensi Responden Berdasarkan Masa Kerja

\begin{tabular}{lll}
\hline Masa Kerja & Frekuensi & Persentase $(\%)$ \\
\hline$\leq 5$ tahun & 11 & 24 \\
$>5$ tahun & 34 & 76 \\
\hline Total & 45 & 100 \\
\hline \multicolumn{2}{c}{ Sumber: Data Primer Tahun 2021. }
\end{tabular}

Tabel 5

Distribusi Frekuensi Responden Berdasarkan Sikap Kerja

\begin{tabular}{lll}
\hline Sikap Kerja & Frekuensi & Persentase (\%) \\
\hline Ergonomis & 8 & 18 \\
Tidak Ergonomis & 37 & 82 \\
\hline Total & 45 & 100 \\
\hline \multicolumn{2}{c}{ Sumber: Data Primer Tahun 2021. }
\end{tabular}

Tabel 6

Hubungan Umur dengan Kelelahan Kerja pada Pekerja Industri Mebel di Kecamatan Tempe Kabupaten Wajo

\begin{tabular}{|c|c|c|c|c|c|c|c|}
\hline \multirow{3}{*}{ Umur } & \multicolumn{4}{|c|}{ Kelelahan Kerja } & \multirow{3}{*}{ Total } & \multirow{3}{*}{$\%$} & \multirow{3}{*}{$\begin{array}{l}\text { Uji Statistik } \\
P\left(x^{2}\right.\end{array}$} \\
\hline & \multicolumn{2}{|c|}{ Lelah } & \multicolumn{2}{|c|}{ Tidak Lelah } & & & \\
\hline & $n$ & $\%$ & $n$ & $\%$ & & & \\
\hline Muda & 9 & 75 & 3 & 25 & 12 & 100 & 0,074 \\
\hline Tua & 31 & 94 & 2 & 6 & 33 & 100 & \\
\hline
\end{tabular}

Sumber: Data Primer Tahun 2021. 
Jurnal Sulolipu : Media Komunikasi Sivitas Akademika dan Masyarakat

Vol. 21 No.2 2021

e-issn : 2622-6960, p-issn : 0854-624X

Tabel 7

Hubungan Lama Kerja dengan Kelelahan Kerja pada Pekerja Industri Mebel di Kecamatan Tempe Kabupaten Wajo

\begin{tabular}{|c|c|c|c|c|c|c|c|}
\hline \multirow{3}{*}{$\begin{array}{l}\text { Lama } \\
\text { Kerja }\end{array}$} & \multicolumn{4}{|c|}{ Kelelahan Kerja } & \multirow{3}{*}{ Total } & \multirow{3}{*}{$\%$} & \multirow{3}{*}{$\begin{array}{l}\text { Uji Statistik } \\
P\left(x^{2}\right.\end{array}$} \\
\hline & \multicolumn{2}{|c|}{ Lelah } & \multicolumn{2}{|c|}{ Tidak Lelah } & & & \\
\hline & $\mathrm{n}$ & $\%$ & $\mathrm{n}$ & $\%$ & & & \\
\hline$\leq 8$ jam & 9 & 69 & 4 & 31 & 13 & 100 & 0,007 \\
\hline$>8 \mathrm{jam}$ & 31 & 97 & 1 & 3 & 31 & 100 & \\
\hline
\end{tabular}

Tabel 8

Hubungan Masa Kerja dengan Kelelahan Kerja pada Pekerja Industri Mebel di Kecamatan Tempe Kabupaten Wajo

\begin{tabular}{|c|c|c|c|c|c|c|c|}
\hline \multirow{3}{*}{ Masa Kerja } & \multicolumn{4}{|c|}{ Kelelahan Kerja } & \multirow{3}{*}{ Total } & \multirow{3}{*}{$\%$} & \multirow{3}{*}{$\begin{array}{l}\text { Uji Statistik F } \\
\left(\mathrm{x}^{2}\right.\end{array}$} \\
\hline & \multicolumn{2}{|c|}{ Lelah } & \multicolumn{2}{|c|}{ Tidak Lelah } & & & \\
\hline & $\mathrm{n}$ & $\%$ & $\mathrm{n}$ & $\%$ & & & \\
\hline$\leq 5$ tahun & 7 & 64 & 4 & 36 & 11 & 100 & 0,002 \\
\hline$>5$ tahun & 33 & 97 & 1 & 3 & 34 & 100 & \\
\hline
\end{tabular}

Sumber: Data Primer Tahun 2021.

Tabel 9

Hubungan Sikap Kerja denganKelelahan Kerja pada Pekerja Industri Mebel di Kecamatan Tempe Kabupaten Wajo

\begin{tabular}{|c|c|c|c|c|c|c|c|}
\hline \multirow{3}{*}{ Sikap Kerja } & \multicolumn{4}{|c|}{ Kelelahan Kerja } & \multirow{3}{*}{ Total } & \multirow{3}{*}{$\%$} & \multirow{3}{*}{$\begin{array}{l}\text { Uji } \\
\text { Statistik } \\
\mathrm{P}\left(\mathrm{x}^{2}\right.\end{array}$} \\
\hline & \multicolumn{2}{|c|}{ Lelah } & \multicolumn{2}{|c|}{ Tidak Lelah } & & & \\
\hline & $\mathrm{n}$ & $\%$ & $\mathrm{~N}$ & $\%$ & & & \\
\hline Ergonomis & 5 & 62 & 3 & 38 & 8 & 100 & 0,009 \\
\hline Tidak Ergonomis & 35 & 95 & 2 & 5 & 37 & 100 & \\
\hline
\end{tabular}

